\title{
Negative correlation between mycological surfaces pollution in hospital emergency departments and blood monocytes phagocytosis of healthcare workers
}

\author{
SŁAWOMIR LEWICKI ${ }^{1}$, AGATA BIELAWSKA-DRÓZD², IZABELA WINNICKA ${ }^{3}$, \\ PAWE€ LESZCZYŃSKII, PIOTR CIEŚLIK', TERESA KORNIEŁOWICZ-KOWALSKA, \\ JUSTYNA BOHACZ ${ }^{4}$, JOLANTA JAROSZUK-ŚCISEE ${ }^{5}$, EWA SKOPIŃSKA-RÓŻEWSKA ${ }^{3,6}$, \\ JANUSZ KOCIK ${ }^{3}$
}

${ }^{1}$ Department of Regenerative Medicine, Military Institute of Hygiene and Epidemiology, Warsaw, Poland

${ }^{2}$ Biological Threats Identification and Countermeasure Center, Military Institute of Hygiene and Epidemiology, Warsaw, Poland ${ }^{3}$ Laboratory of Epidemiology, Military Institute of Hygiene and Epidemiology, Warsaw, Poland

${ }^{4}$ Faculty of Agrobioengineering, Department of Environmental Microbiology, Laboratory of Mycology, University of Life Sciences in Lublin, Poland

${ }^{5}$ Faculty of Biology and Biotechnology, Department of Environmental Microbiology, Maria Curie Skłodowska University (UMCS), Lublin, Poland

${ }^{6}$ Pathology Department, Biostructure Centrum, Medical University of Warsaw, Warsaw, Poland

\begin{abstract}
The aim of the present study was to find a possible relationship between the presence of yeast and filamentous fungi in hospital emergency departments and the activity levels of blood granulocytes and monocytes in emergency personnel.

The study of mycological pollution was conducted in winter; the samples were collected from 10 Warsaw hospitals emergency departments (HED) and in 10 control locations (office spaces) and included air samples and swabbing of floor and walls. The blood for immunological investigation was taken in spring, from 40 men, 26 to 53 years old, healthcare workers of these departments, who have been working for at least 5 years in their current positions, and from 36 corresponding controls, working in control offices. Evaluation of blood leukocyte subpopulations was done by hematological analyzer and cytometry analysis and monocyte and granulocyte phagocytosis by Phagotest.

There were no significant differences in the level of mycological contamination between the test and control places. The qualitative analysis of the surfaces and air samples revealed a prevalence of strains belonging to Aspergillus spp. and Penicillium spp. genus.

Statistical analysis revealed the existence of negative correlation between the number of phagocytizing blood monocytes and fungi spores content on floor and wall surfaces in hospital emergency departments ( $r=-0.3282, p<0.05$ and positive correlation between the number of phagocytizing monocytes in the blood of office workers and fungi pollution of control offices $(r=0.4421, p<0.01)$.
\end{abstract}

Key words: fungi, Emergency Departments, healthcare workers, phagocytosis.

(Cent Eur J Immunol 2015; 40 (3): 360-365)

\section{Introduction}

This is the first part of our studies carried out on the immunological status of medical emergency workers exposed for many years to hazardous biological agents. According to our knowledge, such studies have not yet been performed, but they may be an important consideration in the development of occupational safety regulations. Poly- morphonuclear granulocytes $(\mathrm{G})$ and mononuclear phagocytes: monocytes and macrophages $(\mathrm{M})$ may play a crucial role in the defense against fungal infections. However, fungi and their products may directly or indirectly inhibit their microbiocidal activity [1-6].

Studies on function of granulocytes and monocytes of emergency medical services workers, constantly exposed

Correspondence: Prof. Ewa Skopińska-Różewska, Military Institute of Hygiene and Epidemiology, Kozielska 4, 01-163 Warsaw, Poland, e-mail: ewaskop@hotmail.com 
to many pathogens for years, and menaced of disturbances in phagocytes function, are missing. The aim of the present study was to discover a possible relationship between the presence of yeast and filamentous fungi in hospital emergency departments and the activity levels of blood granulocytes and monocytes in emergency personnel.

\section{Material and methods}

\section{Sampling}

The study of mycological contamination was conducted in winter; the samples were collected from 10 Warsaw hospitals emergency departments (HED) and in 10 control locations (office spaces) and included air samples and imprints and swabbing of floor and walls. One hundred ten samples were collected from 10 hospitals, among them 9 surface and 2 air samples from every hospital. 100 samples from 10 control offices were taken and 9 surface and 1 air sample from every office. Environmental samples were taken with three methods: swabbing, imprint and collection of bioaerosol (airborne biological particles) samples. In swabbing method, the biological material was taken by sterile swab by using template with dimensions $10 \times 10 \mathrm{~cm}$. Material for microbiological tests was isolated also from the ventilation or the air-conditioning and a computer. In imprinted method special applicator with media (Count Tack CT SI - Biomerieux) was dedicated for fungi. These samples were taken from flat surfaces of walls and floors. Air sampling was carried out with Coriolis Recon apparatus (Bertin, France) based on the technology of the humid cyclone. It enables the collection of airborne biological particles of size ranging from $0.5 \mu \mathrm{m}$ to $10 \mu \mathrm{m}$ in the liquid sample. The air sample was implemented by rotating and simultaneously injecting the liquid. As a result of the centrifugal force the implemented particles were separated from the air and concentrated in the liquid. The speed of the air flow at apparatus was $600 \mathrm{l} / \mathrm{min}$. and sampling time didn't exceed 10 minutes. Next the biological material was put into the plastic container and transported to the microbiological laboratory.

\section{Environmental samples culturing}

COUNT-TACT CT S1 plates containing environmental samples were incubated in $22.5^{\circ} \mathrm{C}(+/-2.5)$. After 5 days the number of yeasts and filamentous fungal colonies were counted and the determined number of colony forming units (CFU) per plate (Petri dish) was expressed as CFU number per $25 \mathrm{~cm}^{2}$ of surface area. Swab samples were collected using cotton swabs and placed onto Columbia Agar and Sabouraud Dextrose Agar media (Graso Biotech). The plates were incubated for $24 \mathrm{~h}$ at $37^{\circ} \mathrm{C}$ and $28^{\circ} \mathrm{C}$, respectively. Assay samples for airborne fungi were then filtered with 0.22 $\mu \mathrm{m}$ filter (Merck Millipore, Poland) using Millipore Vaccum Pump P504 (Merck Millipore, Poland). The filters were placed on the surface of Sabouraud Dextrose Agar medium
(Graso Biotech, Poland) and incubated during $72 \mathrm{~h}$ period at $28^{\circ} \mathrm{C}$ for determination of fungi per cubic meter of air [7].

\section{Identification of fungi in environmental samples}

The colonies grown on plates with Sabouraud medium were transferred onto slants with PDA (Potato Dextrose Agar) medium with the following composition: $1000 \mathrm{ml}$ of potato infusion, $20 \mathrm{~g}$ of glucose, $20 \mathrm{~g}$ of agar in order to obtain pure cultures. Afterwards, the microcultures have been obtained on the discs with this medium placed in a humid chamber. Microcultures were incubated in $26^{\circ} \mathrm{C}$ for 3-7 days. One species of vegetative mycelium were identified to genus and species. The identification process was based on macroscopic observation carried out on slants, plates and microscopic assessment in microcultures. The focus of macroscopic observations was on the following features: mycelia colour as well as its structure and pigmentation. Microscopic evaluation focused on examining the structure of vegetative mycelium and reproductive organs of fungi i.e. conidia and conidiophores. The final species identification was made on the basis of the taxonomy studies by Domsch et al. (1980) [8], Barnett and Hunter (1980) [9] and Ellis (1971) [10]. The microscopic observations employed Olympus BX41 laboratory microscope equipped with a digital camera CVIII4 integrated with a computer using Cell-A software for analysis, recording and storing images.

\section{Immunological studies}

Immunological studies were conducted in spring. Blood for immunological investigation was taken from 40 men, 26 to 53 years old, health care workers of these departments, who have been working for at least 5 years in their current positions and from 36 corresponding controls, who worked in control offices, without a history of systemic, inflammatory or immunological diseases. Evaluation of blood leukocyte subpopulations was done by hematological analyzer and cytometry analysis, and monocyte and granulocyte phagocytosis by Phagotest.

Informed consent from study participants and a permission of Local Ethical Committee were obtained.

\section{White blood morphology}

The total number of white blood cells was measured in EDTA blood sample using hematological analyzer in accordance with the manufacturer's protocol (Exigo Vet, Boule Medical AB, Sweden). Next the cytometry assay was performed. FSC/SSC parameters and immunostaining of CD45 were used for percentage white blood cells population determination (lymphocytes, monocytes, neutrophils, basophils, eosinophils). The absolute number of each population in $\mathrm{ml}$ of blood was counted from proportion of $\%$ (cytometry analysis) and total WBC number (hematological analyzer). Results are presented as a mean \pm SD. 


\section{Phagocytic activity of granulocytes and monocytes}

Phagocytosis was performed by commercial Phagotest $^{\mathrm{TM}}$ kit (Glycotope-Biotechnology), according to the instructions provided by the manufacturer. Whole blood samples $(100 \mu \mathrm{l} /$ test $)$ and FITC labeled E. coli were pre-incubated on ice bath $(0 \mathrm{C}, 10 \mathrm{~min})$. Afterwards negative sam-

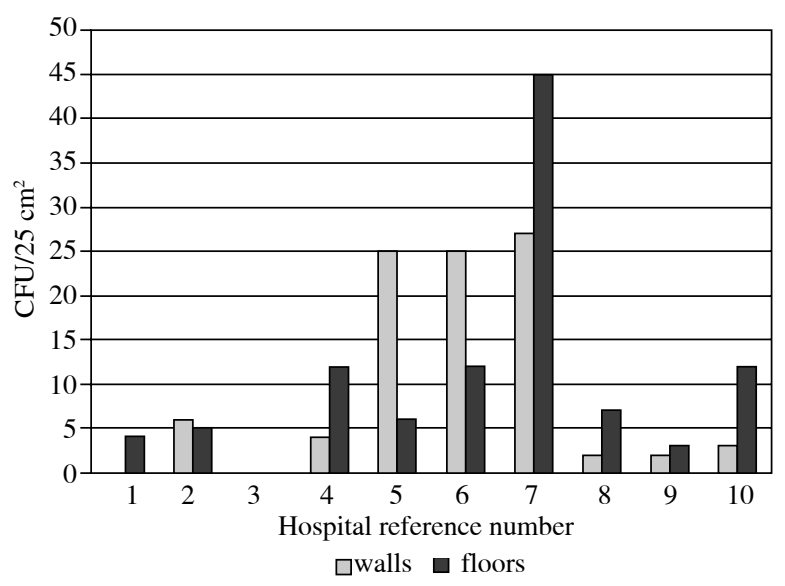

The mean values of the total number of fungi collected in samples were:

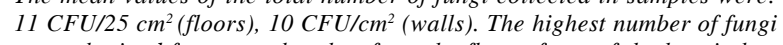
were obtained from sample taken from the floor of one of the hospitals $45 \mathrm{CFU} / 25 \mathrm{~cm}^{2}$. In one case of a hospital, any fungi were detected.

Fig. 1. Total number of fungi determined in contact samples collected from hospital emergency departments

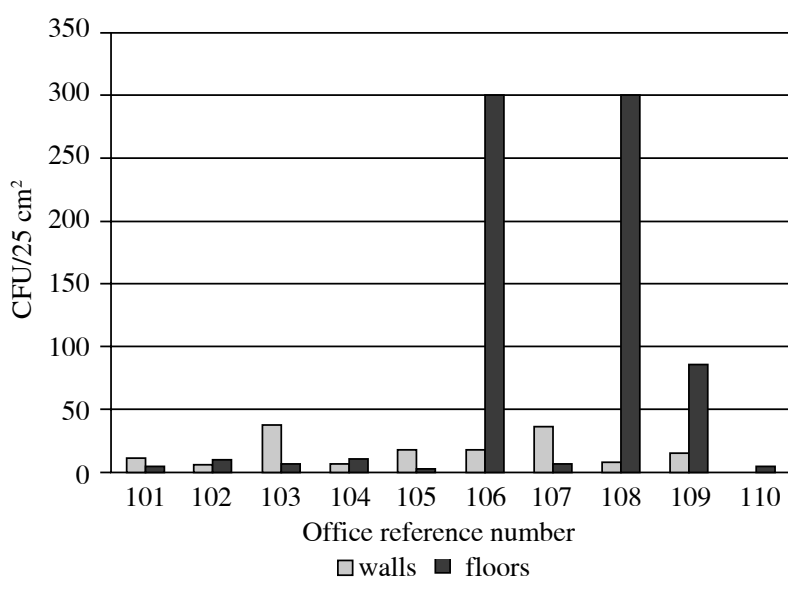

The mean values of the total number of fungi in samples collected from ten control areas by imprinting method were: $73 \mathrm{CFU} / 25 \mathrm{~cm}^{2}$ (walls), and 16 $C F U / 25 \mathrm{~cm}^{2}$ (floors). The number of fungi was higher on the floors than walls. The highest number of fungi was cultured from samples taken from floors in 2 control areas (No106, No108) - $300 \mathrm{CFU} / \mathrm{cm}^{2}$. The lowest values were obtained for samples collected from the number 105. In the case of the walls, the highest number of fungi $\left(38 \mathrm{CFU} / \mathrm{cm}^{2}\right)$ was obtained from samples taken from the control area (No103). In case of sample 110 no fungi were isolated.

Fig. 2. Total number of fungi determined in contact samples collected from control places ple was kept in ice bath at $0^{\circ} \mathrm{C}$ and the test sample was incubated in water bath at $37^{\circ} \mathrm{C}$ (10 minutes). Subsequently, a quenching solution was added to each sample to stop the reaction. Samples, after erythrocytes lysis were stained with DNA bounding dye and analyzed by flow cytometry (FACS Calibur, BD, CellQuestTM software). Percentages of neutrophiles and monocytes phagocytosis were determined. Results are presented as mean percentage \pm SD.

Statistical evaluation of the results was done by Pearson's correlation analysis, Kruskall-Wallis test and unpaired $t$ test (GraphPadPrism).

\section{Results}

\section{Fungi examination}

The results of fungi quantitative analysis collected by imprint method from walls and floors are presented in Fig. 1 (hospital emergency departments) and Fig. 2 (control offices). The results of assay samples for airborne fungi are presented in Fig. 3. Statistical analysis performed with Kruskall-Wallis test did not reveal significant differences between hospital emergency spaces and office rooms in respect to the number of fungi in air (Table 1).

In emergency departments rooms the range of the number of fungi on surfaces was from 0 to $45 \mathrm{CFU} / 25 \mathrm{~cm}^{2}$ (floors) and from 0 to $27 \mathrm{CFU} / 25 \mathrm{~cm}^{2}$ (walls). In office rooms the level of fungi contamination was from 0 to 38 $\mathrm{CFU} / 25 \mathrm{~cm}^{2}$ (floors) and from 2 to $300 \mathrm{CFU} / 25 \mathrm{~cm}^{2}$ (walls) (Fig. 1, Fig. 2). In bio-aerosol samples the number of fungi was from 0 to $19 \mathrm{CFU} / \mathrm{m}^{3}$ (emergency departments rooms) and in office rooms from 0 to $25 \mathrm{CFU} / \mathrm{m}^{3}$ (Fig. 3).

The qualitative analysis of the surfaces and air samples revealed a prevalence of genus Aspergillus spp. and Penicillium spp. Some of them, including Aspergillus fumigatus, Candida spp., Aspergillus niger, Aspergillus flavus may be dangerous for workers as a potential source of mycotoxins and allergic reactions. In mould fungi testing, their widespread presence was not observed in the analysed locations of the hospital environment. Among the fungi found, the prevalent species belonged to the genera Aspergillus spp., Penicillium spp. and Trichoderma spp. The most common species were: Aspergillus niger, Aspergillus fumigatus, Penicillium expansum, Trichoderma koningii. In the samples collected by swabbing the prevalent species were Aspergillus niger and Penicillium expansum. Moreover, in one case it was possible to culture Candi$d a$ spp. In two samples, where one was collected from a hospital emergency department and the other one from a control location, Aspergillus fumigatus was found, which is a pathogenic fungus species. Also in three control locations non-pathogenic species belonging to Penicillium spp. were found and in one control location Aspergillus versicolor was identified. In the case of air samples obtained from hospital emergency departments it was possible to 


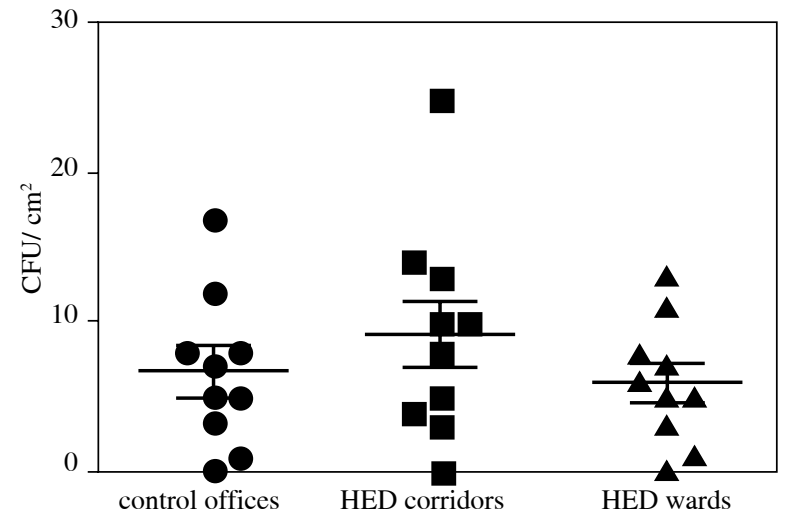

The highest number of fungi obtained in the corridor of one hospital emergency departments was $25 \mathrm{CFU} / \mathrm{m} 3$. In the rooms of hospital emergency departments the highest number of fungi was $13 \mathrm{CFU} / \mathrm{m} 3$. In the one case of hospital there weren't any yeasts and filamentous fungi in the air.

The highest number of fungi in the bioaerosol samples from offices was 19 $\mathrm{CFU} / \mathrm{m} 3$. In two office rooms there weren't any yeasts and filamentous fungi in the air.

Fig. 3. Mycological air pollution

culture a number of (mainly non-pathogenic) species such as Penicillium expansum, Chaetomium globosum, Ulocladium atrum and Trichoderma koningii. One emergency department was a source of samples containing Aspergillus flavus. Furthermore, various species belonging to the Candida spp. were found in hospital emergency rooms as well as Aspergillus niger.

\section{Immunological study}

There were no statistical differences between emergency and office workers in respect to: age, leukocytes number, percentage of leukocytes subpopulations and percentage of phagocytizing granulocytes and monocytes (Table 2). Statistical analysis revealed the existence of negative correlation between the number of phagocytizing blood monocytes and mould spores content on floor and wall surfaces in hospital emergency departments $(r=-0.3282$, $p<0.05$ ) (Fig. 4). A similar tendency can be observed in the case of granulocytes, however statistically non-significant. There was no correlation between the number of spores in air and granulocytes and monocytes phagocytosis of HED healthcare workers. No correlations were found between control offices air and surfaces mycological pollution and granulocytes phagocytosis of their workers. Pearson's analysis revealed the existence of positive correlation between the number of phagocytizing monocytes in the blood of offices workers and fungi pollution of control offices walls and floors $(r=0.4421, p<0.01)$ (Fig. 5).

\section{Discussion}

The project titled "Identification of biological hazards in rescue operations and their impact on the competence

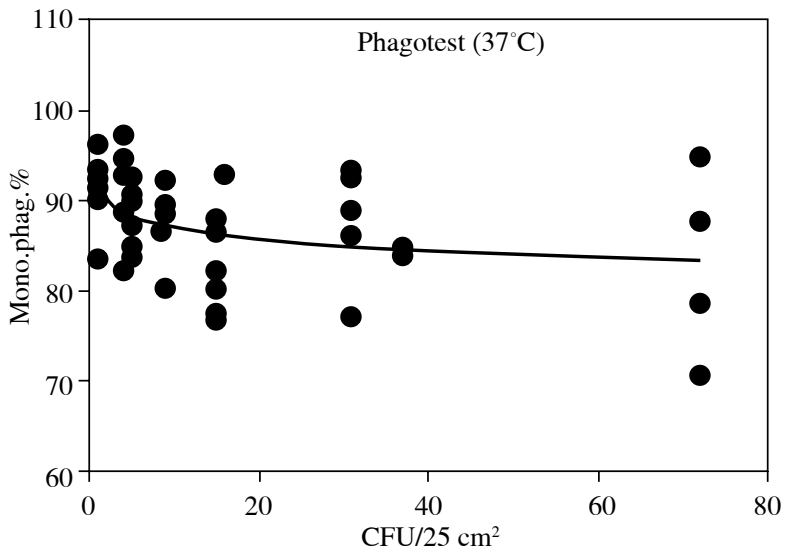

\begin{tabular}{|c|c|}
\hline Number of XY paris & 40 \\
\hline Pearson $r$ & -0.3283 \\
\hline $95 \%$ CI & -0.5805 to -0.01857 \\
\hline$p$ value (two tailed) & 0.0386 \\
\hline$p$ value summary & Yes \\
\hline $\begin{array}{c}\text { Is the correlation significant? } \\
(\alpha=0.05)\end{array}$ & 0.1077 \\
\hline$r$ squared & \\
\hline
\end{tabular}

Fig. 4. Negative correlation between the \% of phagocytizing monocytes in the blood of healthcare workers and the number of fungi spores per $25 \mathrm{~cm}^{2}$ of floor and wall surfaces hospital emergency departments

Table 1. Statistical evaluation of the results of air pollution analysis

\begin{tabular}{|c|c|c|}
\hline \multicolumn{3}{|l|}{ Kruskal-Wallis test } \\
\hline$P$ value & 0.5579 & \\
\hline $\begin{array}{l}\text { Exact or approximate } \\
P \text { value? }\end{array}$ & $\begin{array}{c}\text { Gaussian } \\
\text { Approximation }\end{array}$ & \\
\hline$P$ value summary & ns & \\
\hline $\begin{array}{l}\text { Do the medians vary signif. } \\
(p<0.05)\end{array}$ & No & \\
\hline Number of groups & 3 & \\
\hline Kruskal-Wallis statistic & 1.167 & \\
\hline $\begin{array}{l}\text { Dunn's Multiple Comparison } \\
\text { Test }\end{array}$ & $\begin{array}{l}\text { Difference } \\
\text { in rank sum }\end{array}$ & $\begin{array}{c}\text { Significant? } \\
p<0.05 ?\end{array}$ \\
\hline $\begin{array}{l}\text { Control offices vs. HED } \\
\text { corridors }\end{array}$ & -3.200 & No \\
\hline $\begin{array}{l}\text { Control offices vs. HED } \\
\text { hospital rooms }\end{array}$ & 0.8000 & No \\
\hline $\begin{array}{l}\text { HED corridors vs. HED } \\
\text { hospital rooms }\end{array}$ & 4.000 & No \\
\hline
\end{tabular}




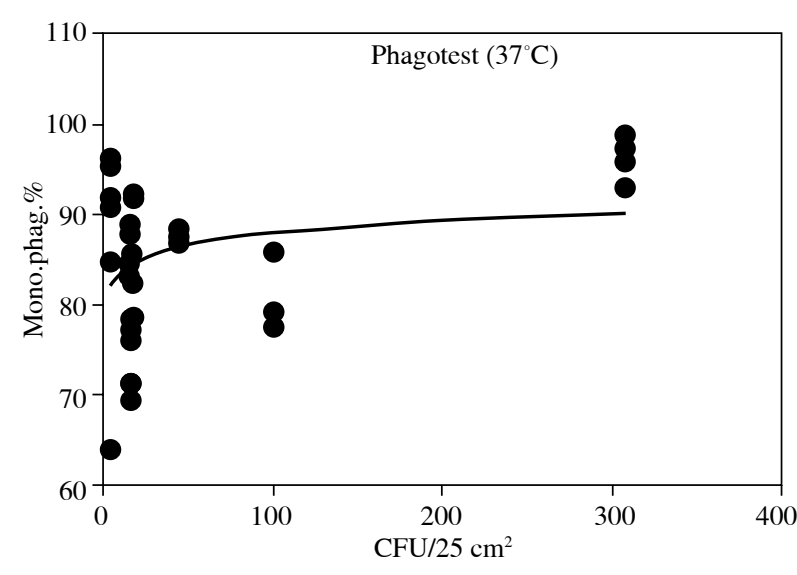

\begin{tabular}{|c|c|}
\hline Number of XY paris & 36 \\
\hline Pearson $r$ & 0.4421 \\
\hline $95 \%$ CI & 0.1327 to 0.6729 \\
\hline$p$ value (two tailed) & 0.0069 \\
\hline$p$ value summary & $* *$ \\
\hline $\begin{array}{c}\text { Is the correlation significant? } \\
(\alpha=0.05)\end{array}$ & Yes \\
\hline$r$ squared & 0.1954 \\
\hline
\end{tabular}

Fig. 5. Positive correlation between the $\%$ of phagocytizing monocytes in the blood of office workers and the number of fungi spores per $25 \mathrm{~cm}^{2}$ of floor and wall surfaces of office rooms

of the immune system for the perspective of health consequences" aims to show to which biological factors the workers of emergency departments of Warsaw hospitals are exposed, and how these factors may influence their immune system. In this paper we present the results of the study conducted in 10 Warsaw hospitals emergency departments, on the phagocytic activity of blood leukocytes, collected from their healthcare workers, and on possible relationship between this activity and mycological contamination of these locations.
We observed negative correlation between the number of fungi measured on walls and floors by imprinting method and emergency departments staff blood monocytes phagocytosis. No such correlation was found for fungi in air samples.

Taking into account the presence of fungi spores on surfaces also as a result of sedimentation or the effect of air movement, it seems reasonable to conduct routine analysis of mycological purity of working areas. It was recommended by Gołofit-Szymczak et al. that imprint method (count tack) as well as impact method (air samplers) could be applied in parallel for testing of mycological contamination [11]. The results of our present work suggest that for studying the relationship between mycological pollution of working areas and immunological parameters of workers, count tack method would possibly fare better.

It is difficult to explain a positive correlation observed in the case of control offices workers between monocyte phagocytosis and mycological contamination. The time of their exposition (more than 5 years) and degree of mycological pollution, both from quantitative and qualitative point of view, was the same as in the case of emergency personnel.

For different reasons e.g. lack of appropriate air-filtering (or air-condition) systems in hospital locations or limited sanitary activities (insufficient cleaning of walls and ventilation grille), lack of relevant maintenance (regular painting of walls) or simply better sanitary conditions of control offices in the past, exposure of emergency departments workers to various biological agents including yeasts, fungi spores and filaments would be higher. Positive correlation observed in office workers may indicate the presence of earlier changes in monocytes reactivity induced by contact with fungi and manifested as stimulation, and negative correlation in emergency workers would be connected with more advanced changes, manifested as disturbed phagocytosis.

Mycological contamination of working areas is dangerous. Except of mycotoxins of Aspergillus spp. and Penicillium spp., antibiotics or hallucinogens may be present too. Inhalation of such particles may lead to disfunction of the immune system [12].

Table 2. Age and blood examination of 40 hospital emergency departments workers and 36 persons working in control offices

\begin{tabular}{|c|c|c|c|c|c|c|c|c|}
\hline & \multicolumn{8}{|c|}{ MEAN \pm SD } \\
\hline & AGE & $\mathrm{WBC} \times 10^{3}$ & $\mathbf{L} \%$ & G\% & М\% & EOS\% & PhagoG\% & PhagoM\% \\
\hline \multirow[t]{2}{*}{ Office workers } & 38.90 & 6.36 & 27.82 & 59.53 & 6.90 & 3.41 & 93.24 & 85.18 \\
\hline & \pm 7.55 & \pm 1.05 & \pm 6.82 & \pm 7.62 & \pm 1.39 & \pm 2.53 & \pm 10.12 & \pm 8.01 \\
\hline \multirow[t]{2}{*}{ HED workers } & 36.5 & 5.88 & 26.8 & 61.54 & 6.44 & 3.09 & 96.83 & 87.33 \\
\hline & \pm 7.97 & \pm 1.45 & \pm 7.71 & \pm 9.22 & \pm 1.42 & \pm 2.56 & \pm 3.10 & \pm 6.05 \\
\hline $\begin{array}{l}\text { Significance } \\
\text { of differences }\end{array}$ & n.s & n.s & n.s & n.s & n.s & n.s & n.s & n.s \\
\hline
\end{tabular}


The qualitative analysis of the surfaces and air samples collected from emergency departments and control offices revealed mainly a prevalence of Aspergillus spp. and Penicillium spp. Among Aspergillus spp. highly pathogenic Aspergillus fumigatus and Aspergillus flavus were found together with a relatively nonpathogenic Aspergillus niger.

According to Pląskowska et al. [13] closed worker areas without air conditioning systems are reservoirs of Aspergillus spp., Cladosporium spp., and Penicillium spp., which was confirmed by our study. Mainly, presence of pathogenic Aspergillus spp. and Penicillium spp. with their allergenic capabilities, mycotoxins producing (eg. Aspergillus fumigatus and Aspergillus flavus) and the ability for opportunistic infections, present a real risk to the health of people working in these areas. It is known that Aspergillus fumigatus mycotoxins have an anti-phagocytic activity regarding macrophages and inhibit cytotoxicity of Tc lymphocytes, and also inhibit the formation of acid phagolysosome [14, 15].

Aspergillus fumigatus is a common pathogen to animals and humans, causing aspergillosis and allergies. Its secondary metabolites display anti-phagocytic and immunomodulating activity in vitro [14] and in vivo [3]. Studies performed ex vivo on granulocytes collected from the blood of patients with cystic fibrosis revealed modulation of their functions by Aspergillus niger. Granulocytes of these patients showed lower myeloperoxidase activity, lower phagocytosis and lower levels of apoptosis in culture, compared to healthy controls [6]. This may be responsible for higher susceptibility of these patients to Aspergillus infection.

Aspergillus flavus is a source of a dangerous mycotoxin, aflatoxin B1 with carcinogenic properties [16] and is the only one found in the list of harmful biological agents in the act (DzU 2005 year, 81, pos. 716). Hepatotoxic and immunotoxic aflatoxin $\mathrm{B}$ is produced by Aspergillus parasiticus also, and is a frequent contaminant of food and animal feed. Dietary exposure to this mycotoxin impairs cell mediated immunity and induces inflammatory response [17]. Phagocytosis and microbicidal activity of human monocytes were significantly impaired by aflatoxin B1 at a very low dose of $0.1 \mathrm{pg} / \mathrm{ml}$ [18]. Reddy and Sharma have found, in their in vivo studies on murine model, a dose-related decrease of: lymphocytes proliferative activity, peripheral leukocyte counts and natural killer cell function. In vitro aflatoxin B1 reduced generation of suppressor cells [19].

This article was supported by project number II.P.19 (contract number 42/2014/PW-PB) titled "Identification of biological hazards in rescue operations and their impact on the competence of the immune system in the perspective of health consequence" carried out under the Program titled "Improving safety and working conditions" led by Central Institute for Labour Protection- National Research Institute.

The authors declare no conflict of interest.

\section{References}

1. Swamydas M, Break TJ, Lionakis MS (2015): Mononuclear phagocyte-mediated antifungal immunity: the role of chemotactic receptors and ligands. Cell Mol Life Sci 72: 2157-2175.

2. Fogle MR, Douglas DR, Jumper CA, Straus DC (2007): Growth and mycotoxin production by Chaetomium globosum. Mycopathologia 164: 49-56.

3. Singh K, Pathak SC (2010): Effect of Aspergillus fumigatus infection on cellular and humoral immune responses in red cotton stainer, Dysdercus similis (Heteroptera: Pyrrhocoridae). Biological Forum - An International Journal 2(1): 9-11.

4. Ratti BA, Godoy JS, de Souza Bonfim Mendonca P, et al. (2015): Microbiocidal activity of neutrophils is inhibited by isolates from recurrent vaginal candidiasis (RVVC) caused by Candida albicans through fungal thioredoxin reductase. Cell Immunol 293: 22-29.

5. Chidananda C, Vasantha KY, Sattur AP (2015): Sclerotiorin is non-mutagenic and inhibits human PMNL 5-lipoxygenase and platelet aggregation. Indian J Exp Biol 53: 228-231.

6. Bokonijic DR, Vucevic D, Minic P, et al. (2011): Modulation of granulocyte function by the infuence of Aspergillus niger and Toll like receptor agonists in children suffering from cystic fibrosis. Ped Respir Rev 12 (Suppl 1): 83.

7. Buttner MP, Willeke K, Grinshpun S (2003): Sampling and analysis of airborne organisms.- In: Manual of Environmental Microbiology $2^{\text {nd }}$ ed. (ed. Hurst C, Crawford RL, Knudsen GR et al.). ASM Press, Washington CD; 814-826.

8. Domsch KH, Gams W, Anderson TH (1980): Compendium of Soil Fungi. Acad Press London.

9. Barnett HL, Hunter BB (1998): Illustrated Genera of Imperfect Fungi, Fourth Edition. APS Press.

10. Ellis MB (1971): Dematiaceous Hyphomycetes. The Eastern Press London.

11. Gołofit-Szymczak M, Ławniczek-Wałczyk A, Górny RL (2013): Ilościowa i jakościowa kontrola szkodliwych czynników biologicznych w środowisku pracy. Podstawy i Metody Oceny Środowiska Pracy 2: 5-17.

12. Charkowska A (2003): Zanieczyszczenia w instalacjach klimatyzacyjnych i metody ich usuwania. ISBN 83-91 3895-7X, IPPU MASTA, 1-60.

13. Pląskowska E, Korol M, Ogórek R (2012): Fungi found in air-conditioned room. Part II. Mykologia Lekarska 19: 27-36.

14. Múllbacher A, Waring P, Eichner RD (1985): Identification of agent in culture of Aspergillus fumigatus displaying anti-phagocytic and immunomodulating activity in vitro. J Gen Microbol 131: 1251-1258.

15. Slesiona S, Gressler M, Mihlan M (2012): Persistence versus Escape: Aspergillus fumigatus employ different strategies during interactions with macrophages. PLOS ONE 7: e31223.

16. Saad-Hussein A, Taha MM, Beshir S, et al. (2014): Carcinogenic effects of aflatoxin B1 among wheat handlers. Int J Occup Environ Health 20: 215-219.

17. Meissonnier GM, Pinton P, Laffitte J, et al. (2008): Immunotoxicity of aflatoxin B1: impairment of the cell-mediated response to vaccine antigen and modulation of cytokine expression. Toxicol Appl Pharm 231: 142-149.

18. Casumano V, Rossano F, Merendino RA, et al. (1996): Immunobiological avtivites of mould products: functional impairment of human monocytes exposed to aflatoxin B1. Res Microbiol 147: 385-391.

19. Reddy RV, Sharma RP (1989): Effects of aflatoxin B1 on murine lymphocytic functions. Toxicology 54: 31-44. 